\title{
Real-time adsorption of exo- and endoglucanases on cellulose: Effect of pH, temperature and inhibitors
}

Peiqian Zhang, ${ }^{\dagger}$ Mimi Chen, ${ }^{\dagger}$ Yuhao Duan,${ }^{\dagger}$ Renliang Huang,,${ }^{\ddagger}$ Rongxin Su, $,{ }^{*}, \S$ Wei Qi $,{ }^{\dagger}, \S$ Wim Thielemans, ${ }^{*}, \#$ and Zhimin $\mathrm{He}^{\dagger}$

$\dagger$ State Key Laboratory of Chemical Engineering, Tianjin Key Laboratory of Membrane Science and Desalination Technology, School of Chemical Engineering and Technology, Tianjin University, Tianjin 300072, PR China

${ }^{\ddagger}$ School of Environmental Science and Engineering, Tianjin University, Tianjin 300072, PR China

$\S$ Collaborative Innovation Center of Chemical Science and Engineering (Tianjin), Tianjin 300072, PR China

\# Renewable Materials and Nanotechnology Group, Department of Chemical Engineering, KU Leuven, Campus Kortrijk, Etienne Sabbelaan 53, 8500 Kortrijk, Belgium

\section{*Corresponding author.}

E-mail: surx@tju.edu.cn (R. Su),wim.thielemans@kuleuven.be (W. Thielemans) 


\section{ABSTRACT}

Effective regulation of cellulase adsorption is key to improving the efficiencies of the two major bottlenecks of lignocellulose hydrolysis and cellulase recovery. In this work, we investigated the effect of inhibitors, $\mathrm{pH}$, and temperature on the adsorption of exo- and endoglucanases (Cel7A and Cel7B, respectively) on cellulose using quartz crystal microgravimetry with dissipation. The addition of glucose and cellobiose can both inhibit the hydrolysis activity of Cel7A, whereas only cellobiose can inhibit that of Cel7B. Notably, the adsorption was favored by acidic conditions $(\mathrm{pH} \leq 4.8)$ and low temperature, whereas alkaline conditions (pH 9 and 10) facilitated enzyme desorption, which is useful to guide the process of cellulase recovery. The adsorption and hydrolysis activity of Cel7A and Cel7B were both higher at $45{ }^{\circ} \mathrm{C}$ than at $25{ }^{\circ} \mathrm{C}$. These findings pave the way to effective regulation of cellulase adsorption and thus improve lignocellulose conversion and cellulase recovery.

KEYWORDS: cellulose; cellulase; exoglucanase (Cel7A); endoglucanase (Cel7B); adsorption; kinetics; quartz crystal microgravimetry with dissipation (QCM-D) 


\section{INTRODUCTION}

Lignocellulose, the most abundant renewable biomass resource, is commonly subjected to enzymatic hydrolysis to release sugars required for the production of liquid fuels and bio-based chemicals; $;^{1,2}$ therefore, the above process is of great significance for the creation of a sustainable circular economy. ${ }^{3}$ An important prerequisite for enzymatic hydrolysis is the effective adsorption of cellulases on the surface of lignocellulose, ${ }^{4-6}$ which can be either reversible or irreversible. ${ }^{7-9}$ After hydrolysis, some cellulases are released into the supernatant (liquid phase), while others stay attached to the residual substrate (solid phase). Although solution-phase cellulases can be re-adsorbed on fresh substrates for recycling ${ }^{10}$ or be collected by ultrafiltration, ${ }^{11}$ these methods cannot be used to directly recover substrate-bound enzymes. Therefore, the dynamics of cellulase adsorption on cellulose substrates under various conditions needs to be elucidated to be able to modulate lignocellulose hydrolysis and cellulase recovery. ${ }^{12,13}$

The complete deconstruction of solid and recalcitrant cellulose is facilitated by the synergy between two enzyme classes, i.e., cellobiohydrolases (CBHs) and endoglucanases (EGs). ${ }^{14-16}$ Usually, CBHs disrupt the hydrogen-bonded structure of cellulose and dislodge individual cellulose chain ends from the surface, whereas EGs simultaneously combine with these chain ends and cleave individual bonds to yield oligosaccharides with polymerization degrees of 2-6 that are subsequently released into the aqueous solution. ${ }^{17}$ Importantly, the effective adsorption of cellulases requires appropriate conditions, e.g., a change in $\mathrm{pH}$ may alter the conformation of these enzymes and thus affect their adsorption behavior. Previously, we have determined the contents of free cellulases at different $\mathrm{pH}$ and temperatures by means of a traditional analytical method. ${ }^{18}$ However, these experiments were carried out using a mixture of 
cellulases, and only the final adsorption amounts were determined. Quartz crystal microgravimetry with dissipation (QCM-D) has been shown to be a powerful tool to investigate molecular adsorption on surfaces. The adsorption of cellulase on cellulose films was already examined by QCM-D. ${ }^{19-21}$ However, the effect of $\mathrm{pH}$, temperature, and other additives on the real-time adsorption behavior of individual cellulases (CBH or EG) are still not well known and thus require a detailed analysis. The simultaneous occurrence of cellulase adsorption on, reaction with, and desorption from the substrate during lignocellulose conversion suggests that the elimination of enzymatic substrate cleavage by the addition of certain inhibitors should contribute to a better understanding of cellulase adsorption behavior and kinetics. As is well known, cellulase adsorption and hydrolysis can be greatly inhibited by their products including glucose and cellobiose. ${ }^{22,23}$ In addition, Maurer et al. ${ }^{24}$ followed the competitive sorption kinetics of inhibited endoand exoglucanases on model cellulose substrates after the addition of $6000 \mathrm{ppm}$ glucose. Although cellulases can be noncompetitively inhibited by species such as cellobiose and glucose, the effect of these inhibitors on the real-time adsorption of CBHs and EGs have not been reported yet. 


\section{a) The research system}

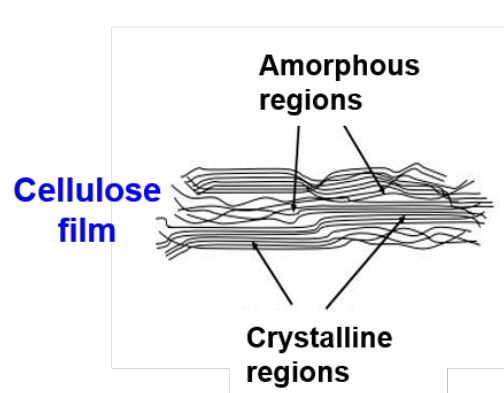

Inhibitor/pH/Temperature

\section{b) Real-time monitor by QCM-D}
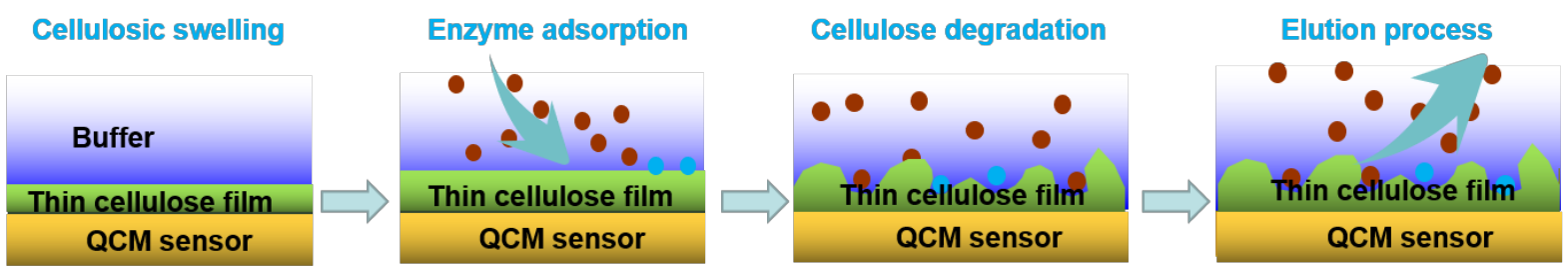

Scheme 1. Schematic illustration of cellulase adsorption/reaction on the surface of cellulose studied by QCM-D. (a) Cellulase adsorption on cellulose and its hydrolysis were carried out in situ under different conditions. (b) The degradation of thin cellulose films on a bare Au sensor could be divided into four stages, with red and blue points representing free and irreversibly adsorbed enzymes, respectively.

Herein, we utilized QCM-D to quantitatively investigate the real-time adsorption of cellulases on cellulose (Scheme 1), employing two cellulases (Cel7A and Cel7B) as representative CBHs and EGs, respectively, and using cellobiose and glucose as inhibitors. The effect of $\mathrm{pH}$ and temperature on cellulase adsorption were also investigated, and the calculated kinetic parameters were analyzed in detail to improve our understanding of the enzyme-substrate interaction mechanism and realize effective enzyme adsorption control.

\section{MATERIALS AND METHODS}

\section{Materials}

Avicel PH-101 was obtained from Sigma-Aldrich (Ireland), poly-diallyl-dimethyl-ammonium 
chloride (PDADMAC, 20\%) and 4-methylmorpholine- $N$-oxide (4MMO, 97\%) were obtained from Sigma-Aldrich (China). Cellobiose was purchased from Aladdin (Shanghai, China). Dimethyl sulfoxide (DMSO, 99.5\%), citric acid, sodium citrate, $\mathrm{NaH}_{2} \mathrm{PO}_{4}, \mathrm{Na}_{2} \mathrm{HPO}_{4}$, glucose, $\mathrm{Na}_{2} \mathrm{CO}_{3}$, and $\mathrm{NaHCO}_{3}$ were purchased from Kermel Corporation (Tianjin, China). Fungal cellulases (isolated from Trichoderma longibrachiatum) typically used for kinetic studies of cellulolytic activity were obtained from Megazyme (Bray, Ireland). ${ }^{25,26}$ Cellobiohydrolase I (Cel7A; Megazyme E-CBHI, $M_{\mathrm{w}}=65,000 \mathrm{Da}$ ) and endoglucanase $\mathrm{I}\left(\mathrm{Cel7B}\right.$, Megazyme E-CELTR, $\left.M_{\mathrm{w}}=57,000 \mathrm{Da}\right)$ were obtained as suspensions in $3.2 \mathrm{M}\left(\mathrm{NH}_{4}\right)_{2} \mathrm{SO}_{4} / 0.02$ wt $\% \mathrm{NH}_{4} \mathrm{~N}_{3}$ at concentrations of 10,000 and 9,400 ppm, respectively. They were then diluted with an aqueous sodium salt buffer/inhibitor solution to the concentrations of 50 and $25 \mathrm{ppm}$, which were equal to $0.77 \mu \mathrm{M}$ and $0.44 \mu \mathrm{M}$ for Cel7A and Cel7B, respectively. The ratio of Cel7 A and Cel7B was based on a previous study, which showed that the degradation rate of cellulose film is fastest when the concentration ratio of Cel7A to Cel7B is $2: 1 .{ }^{27}$ Buffer ionic strength was maintained at $9.5-10 \mathrm{mM}$ throughout the experiments, and deionized (DI) water was obtained using a Milli-Q gradient system (resistivity $>18 \mathrm{M} \Omega$ ).

\section{Fabrication of thin cellulose films}

The quartz crystal sensor was subjected to 10 -min UV-ozone cleaning and placed for 5 min into a 5:1:1 $\mathrm{v} / \mathrm{v} / \mathrm{v}$ mixture of water, aqueous ammonia $(25 \mathrm{wt} \%)$ and hydrogen peroxide $(30 \mathrm{wt} \%)$ held at $75{ }^{\circ} \mathrm{C}$. Subsequently, the sensor was rinsed with water, blown dry with nitrogen, and finally subjected to another 10-min UV-ozone cleaning.

The wafers were subsequently soaked for $30 \mathrm{~min}$ in a $0.5 \% \mathrm{w} / \mathrm{w}$ solution of PDADMAC, which functioned as a cationic polymer anchor between the Au surface and the cellulose film. After deposition 
of the anchor polymer layer, wafers were washed in DI water for $15 \mathrm{~min}$ and subsequently dried. Thin cellulose films were deposited on Au-coated sensors using a modified method of Gunnars et al. ${ }^{28}$ The major modifications were related to solution composition, allowing the deposition of thinner and more rigid cellulose films for QCM analysis. The cooled cellulose solution was deposited on the prepared goldcoated sensors by spin-coating (Spin150-v3-NPP, Sweden) at $5000 \mathrm{rpm}$ for $1 \mathrm{~min}$. Coated wafers were then washed with deionized water for $12 \mathrm{~h}$ without agitation and dried under nitrogen flow. ${ }^{17}$ Typically, Avicel microcrystalline cellulose (105 mg) was dissolved in a mixture of 4MMO (2.640 g) and DI water $(660 \mathrm{~mL})$, and DMSO $(7.5 \mathrm{~mL})$ was subsequently added to adjust solution viscosity and hence control the mass and thickness of the deposited film.

\section{Characterization of cellulose films}

The dried quartz sensor, cellulose-coated, Cel7A-treated, and Cel7B-treated chips were washed with water, dried in a flow of nitrogen gas, and subjected to contact angle measurements (OCA15 contact angle meter, Future Digital Scientific, Long Island, USA) at atmospheric pressure and 50\% relative humidity. The above measurements were performed by placing water droplets on five different points of the sample surface and averaging the obtained values.

The surface morphology of Au-coated, cellulose-coated, Cel7A-treated, and Cel7B-treated chips was characterized by atomic force microscopy (AFM, Agilent 5500, USA) utilizing PointProbe ${ }^{\circledR}$ Plus probes at a scan speed of $0.8 \mathrm{~nm} / \mathrm{s}$ in the tapping mode.

\section{Real-time adsorption of cellulases studied by QCM-D}

The adsorption and activity of cellulases on a flat model cellulose surface was quantified using a 
quartz crystal microbalance. During the above measurements, the frequency shift and dissipation response of the cellulose film were continuously measured at a flow rate of $100 \mu \mathrm{L} / \mathrm{min}$. All experiments were conducted at $25{ }^{\circ} \mathrm{C}$ except for those performed to determine the effect of temperature. All experiments, including those involving cellulose swelling, flow stage, and enzyme adsorption/desorption from the cellulose surface, were repeated five-fold. As mentioned above, the concentrations of Cel7A and Cel7B equaled 50 and $25 \mathrm{ppm}$, respectively.

For rigid films with a sufficiently low dissipation response, such as those used in this work (Figure S1), the $\Delta D / \Delta F$ ratio is less than 0.05 , which allows the mass change to be determined using the Sauerbrey equation. ${ }^{29}$

$$
\Delta \mathrm{m}_{f}=-\frac{\rho_{q} h_{q}}{n f_{0}} \Delta f=-C \Delta f
$$

In the above formula, $\Delta m_{f}=\Delta M_{f} / A_{q}$ is the mass change per unit area, i.e., the surface density change, $A_{q}$ is the surface area of the quartz crystal (the working area of the chip was approximately equal to 0.2 $\left.\mathrm{cm}^{2}\right), \rho_{q}$ is the density of the quartz crystal $\left(2.648 \mathrm{~g} / \mathrm{cm}^{3}\right), h_{q}$ is the thickness of the quartz crystal, $n$ is a multiplier, $f_{0}$ is the fundamental frequency, $\Delta f$ is the frequency change, and $C$ is a constant given by $\rho_{q} h_{q} / n f_{0}$ and equaling $17.7 \mathrm{ng} \mathrm{cm}^{-2} \mathrm{~Hz}^{-1}$ in this particular case. Thus, the change of mass on the film is linearly related to the change in frequency.

Usually, the rate constant for cellulase adsorption is much higher than those for cellulase complexation and desorption. Herein, the initial adsorption rates of Cel7A and Cel7B were calculated based on the dynamic curve region at $t<3 \mathrm{~min}$.

\section{Effect of inhibitors}


A cellulose-coated Au sensor was placed into the flow cell of a quartz crystal microbalance (Q-Sense

E1, Västra Frölunda, Sweden), and the cell was filled with $9.5 \mathrm{mM} \mathrm{NaH}_{2} \mathrm{PO}_{4}$ buffer solution (pH 5.5) containing glucose or cellobiose $(0,3000,6000$, or $12000 \mathrm{ppm})$. The above sugars were utilized as inhibitors of cellulase activity and complexation with cellulose, thus allowing more accurate evaluation of enzyme adsorption behavior. Importantly, the addition of aqueous glucose at this concentration range did not significantly affect the mass of model cellulose films. ${ }^{17}$

\section{Effect of pH}

After cellulose swelling, the flow cell was filled with buffer solutions of variable $\mathrm{pH}(\mathrm{pH} 4$ - 10), i.e., citric acid/sodium citrate ( $\mathrm{pH} 4$ and 4.8), $\mathrm{NaH}_{2} \mathrm{PO}_{4} / \mathrm{Na}_{2} \mathrm{HPO}_{4}\left(\mathrm{pH} 6,7\right.$, and 8), and $\mathrm{Na}_{2} \mathrm{CO}_{3} / \mathrm{NaHCO}_{3}(\mathrm{pH}$ 9 and 10). Enzyme solutions contained glucose (6000 ppm) and cellobiose (3000 ppm).

\section{Effect of temperature}

The temperature of the flow cell was manually adjusted to 25 or $45^{\circ} \mathrm{C}$. The above cell was filled with $9.5 \mathrm{mM} \mathrm{NaH}_{2} \mathrm{PO}_{4}$ buffer (pH 5.5) to swell cellulose. Finally, buffer or a buffer/inhibitor mixture was flowed through the cell to examine enzyme desorption behavior.

\section{RESULTS AND DISCUSSION}

\section{Hydrophobicity and morphology of cellulose film}

Figure 1 shows the static contact angles for four surfaces (bare Au, cellulose-coated, Cel7A-treated cellulose, and Cel7B-treated cellulose chips). The untreated Au chip exhibited the most pronounced hydrophobicity and a static contact angle of $\sim 85^{\circ}$ (Figure 1a). After coating with cellulose, the contact 
angle decreased to $17.6^{\circ}$ (Figure 1b), a value slightly smaller than that reported in the literature, ${ }^{30}$ which indicated that the cellulose layer greatly enhanced the hydrophilicity of the surface when compared to the bare gold surface. Treatment with Cel7A and Cel7B increased the contact angle (Figures 1c and 1d, respectively), which was ascribed to the adsorption of these enzymes onto the cellulose chains and thus enhancing the surface hydrophobicity.

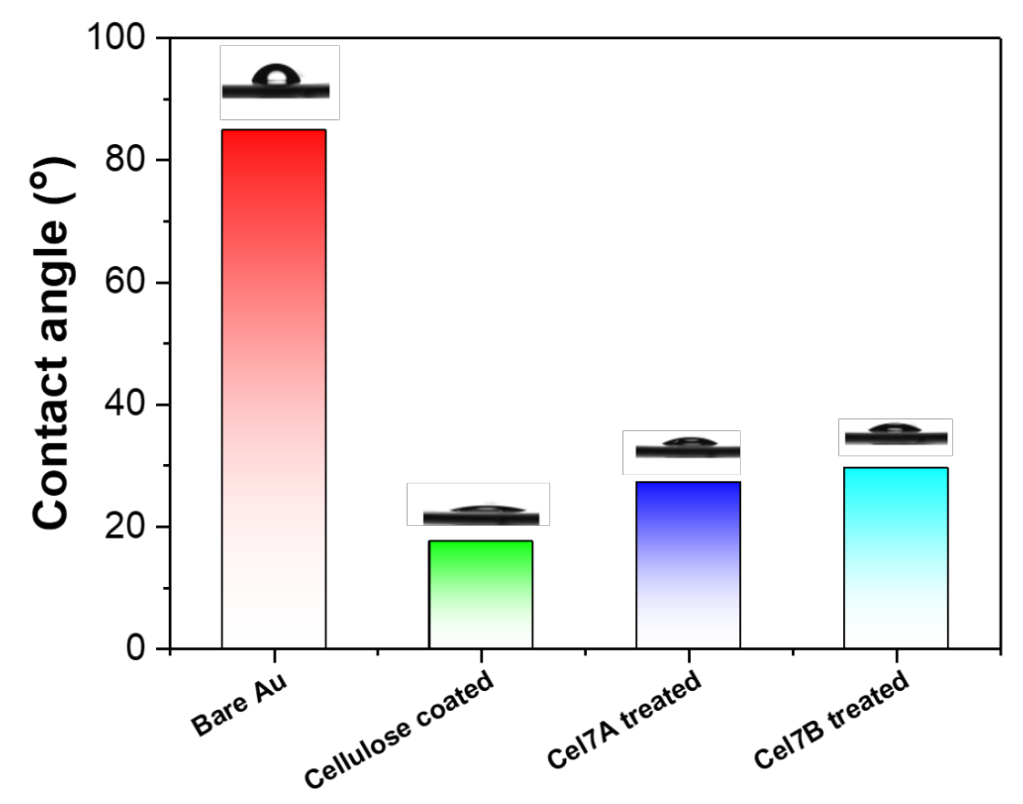

Figure 1. Contact angles of water droplets on bare Au, cellulose-coated, Cel7A-treated, and Cel7B-treated surfaces at $25^{\circ} \mathrm{C}$.

As shown in Figure 2, the untreated Au film had a root mean square (RMS) roughness of $1.05 \mathrm{~nm}$, whereas uniform and evenly distributed protrusions were observed on the surface of cellulose film (Figure $2 \mathrm{~b})$. These protrusions were probably an artifact of nitrogen purging, which resulted in the dry shrinkage and aggregation of cellulose molecular chains. The cellulose-coated chip had an RMS roughness of 2.5 $\mathrm{nm}$, which was higher than that of the bare Au film, and treatment with Cel7A and Cel7B resulted in a further RMS roughness increase (5.8 and $5.1 \mathrm{~nm}$, respectively), as shown in Figures 3c and 3d, 
respectively. This behavior was mainly attributed to the adsorption of Cel7A and Cel7B together with cellulose hydrolysis (Figure S2), which have the similar domain structures (molecular weights of $\sim 55 \mathrm{kDa}$ and dimensions of $\sim 15 \times 5 \times 10 \mathrm{~nm}){ }^{23}$

a)
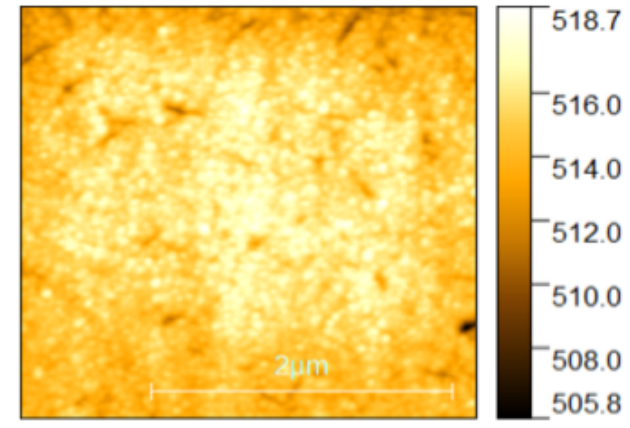

c)

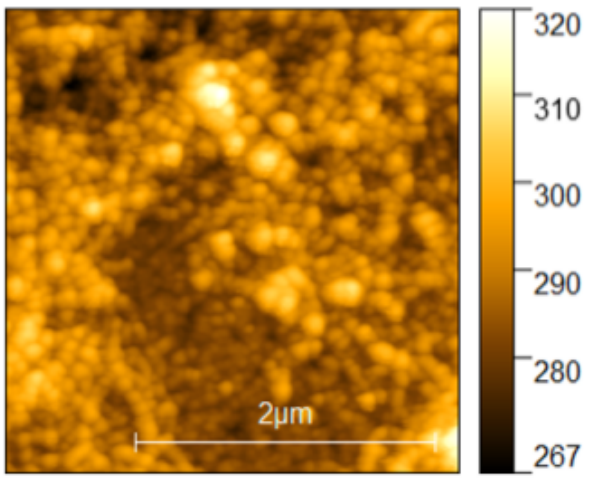

b)

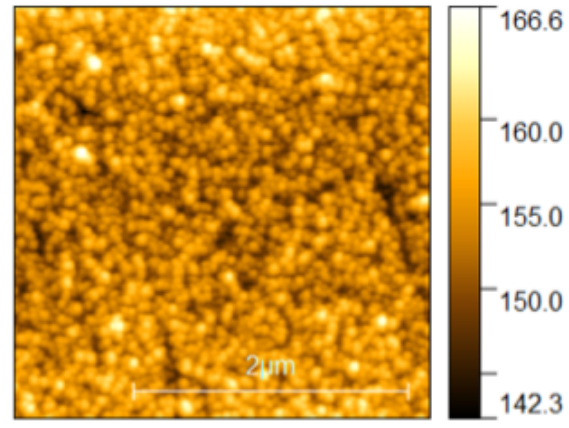

d)

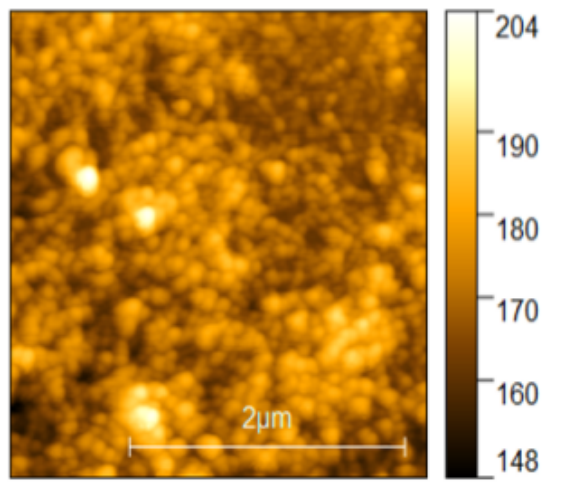

Figure 2. Flattened and topographic AFM images of (a) bare Au, (b) cellulose-coated, (c) Cel7A-treated, and (d) Cel7B-treated surfaces recorded at $25^{\circ} \mathrm{C}$ in the dry state (scale bar $=2 \mu \mathrm{m}$, scanning area size $=$ $3 \times 3 \mu \mathrm{m})$.

\section{Effect of inhibitors on cellulase adsorption and cellulose hydrolysis}

Glucose and cellobiose are the products of cellulose hydrolysis and can thus inhibit enzymatic hydrolysis of cellulose in situ. ${ }^{31,32}$ To examine the behavior of cellulase adsorption in an objective manner, it is better to exclude the influence of cellulose hydrolysis during QCM-D detection. Therefore, glucose 
and cellobiose were added to inhibit cellulose hydrolysis. ${ }^{17}$

Typically, the solutions containing Cel7A and a kind of inhibitor (glucose or cellobiose) were flowed over the cellulose film for $30 \mathrm{~min}$ (Figure 3a), and rapid enzyme adsorption was observed during the initial $800 \mathrm{~s}$ binding. At $800 \mathrm{~s}$, the mass of the adsorbed enzyme ( $\Delta$ mass) in the presence of glucose was lower than that without glucose, which supported our assumption that glucose can slightly inhibit enzymecellulose binding. In the range of $800 \mathrm{~s}-30 \mathrm{~min}, \Delta$ mass remained almost unchanged with time in the presence of glucose, indicating that glucose can significantly inhibit Cel7A-promoted hydrolysis. However, the glucose concentration at the range of 3000-12000 ppm did not significantly affect Cel7A adsorption. Without glucose addition, $\Delta$ mass started to decrease after $800 \mathrm{~s}$ because of cellulose film hydrolysis by Cel7A. After $30 \mathrm{~min}$, the flow of Cel7A solution was stopped, and the enzyme-substrate interaction was examined under static conditions. The continuous and even faster decrease in $\Delta$ mass was observed in the absence of glucose ascribed to the hydrolysis of cellulose film by Cel7A. 

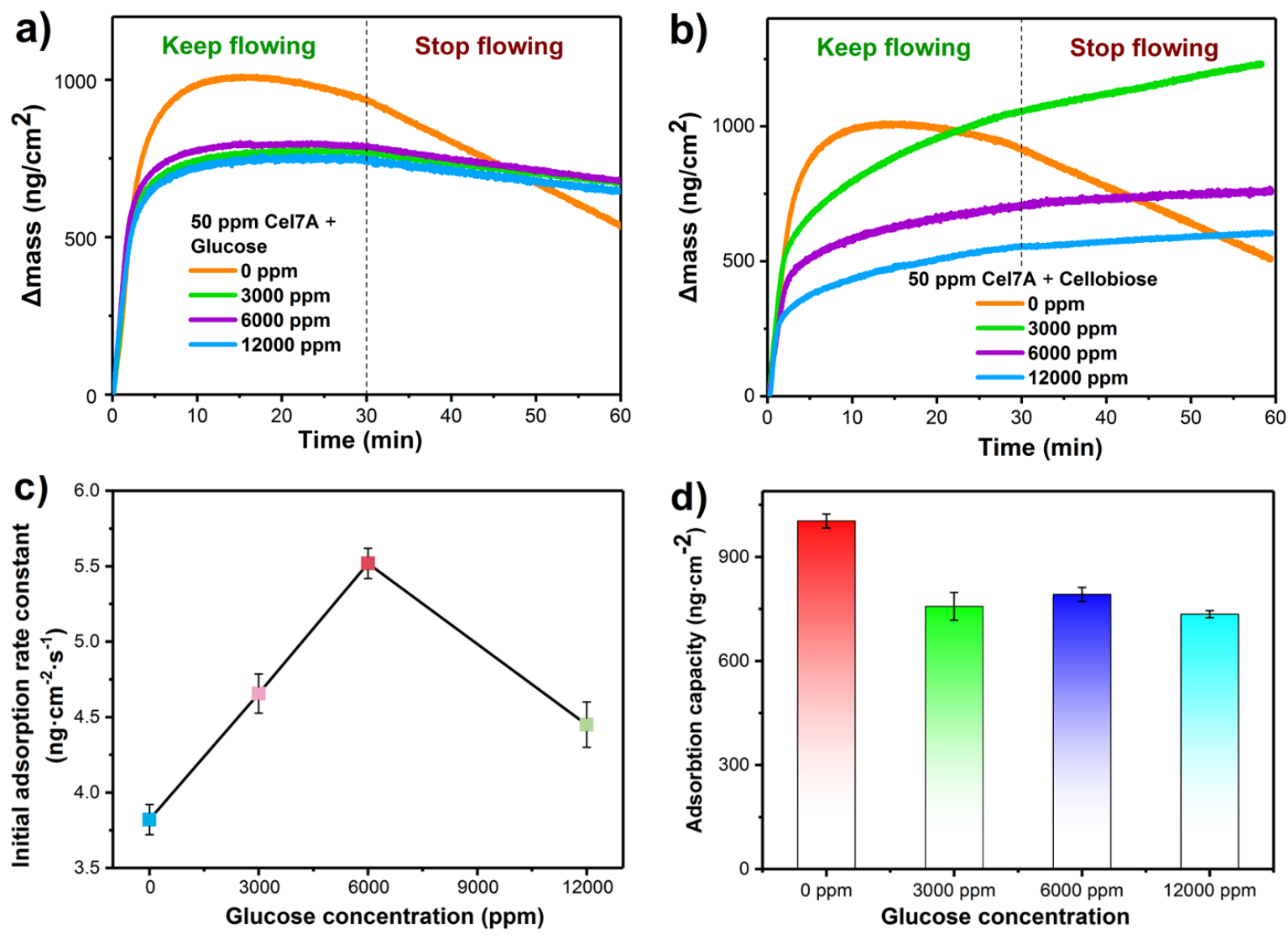

Figure 3. Effects of glucose and cellobiose on Cel7A adsorption on cellulose and its hydrolysis. The flow was stopped after $30 \mathrm{~min}$, as indicated by a vertical dashed line. Buffers containing (a) glucose and (b) cellobiose at concentrations of $0,3000,6000$, and $12000 \mathrm{ppm}$ were used. The concentration of Cel7A in aqueous buffer/inhibitor solutions equaled $50 \mathrm{ppm}$ at $25^{\circ} \mathrm{C}$. (c) Variation of initial adsorption rate constant with glucose concentration. (d) Variation of maximum enzyme adsorption capacity (achieved after $\sim 800$ s) with glucose concentration.

Similar to the case of glucose, the adsorbed amount of Cel7A on the cellulose film decreased with an increasing concentration of cellobiose (Figure 3b), which indicated the pronounced inhibitory effect of cellobiose on Cel7A binding. This behavior was rationalized by the fact that Cel7A is a cellobiohydrolase, which attacks the ends of cellulose chains to yield cellobiose. Therefore, cellobiose is a direct product of cellulose hydrolysis, which might be capable to inhibit the formation of enzyme-cellulose complexes. As 
shown in Figure 3c, the initial rate constant of Cel7A adsorption reached a maximum of $5.52 \mathrm{ng} \mathrm{cm}^{-2} \mathrm{~s}^{-1}$ at a glucose concentration of $6000 \mathrm{ppm}$ (Figure S3). At the same time, the highest Cel7A adsorption capacity was also observed (Figure 4d). Therefore, glucose with the concentration of $6000 \mathrm{ppm}$ was used in subsequent Cel7A experiments, as a comparison with the previous study by Maurer et al. ${ }^{24}$

Figure 4 displays the adsorption behavior of Cel7B on cellulose films with varying concentrations of glucose or cellobiose. As shown in Figure 4a, the mass on the chip started to decrease after $\sim 290 \mathrm{~s}$ without added inhibitor (cf. $800 \mathrm{~s}$ in Figure 3a), demonstrating that Cel7B hydrolyzed the cellulose film more efficiently than Cel7A. ${ }^{33,34}$ In addition, Cel7B hydrolysis could not be efficiently inhibited at the low glucose concentrations (i.e. 3000 and $6000 \mathrm{ppm}$ ). Although a high concentration of $12000 \mathrm{ppm}$ could slow down the decrease in the mass on the chip, the hydrolysis of cellulose film was still obvious. Therefore, it is clear that glucose was not an efficient inhibitor of Cel7B, even though it was used in the previous study. ${ }^{24}$

As illustrated in Figure 4b, Cel7B hydrolysis was effectively inhibited by cellobiose at concentrations of 3000-12000 ppm. There was no change in the mass on the chip after $\sim 1000 \mathrm{~s}$ in the presence of cellobiose. The initial adsorption rate constant decreased with the increasing cellobiose concentration (Figure 4c). As shown in Figure 4d, the Cel7B adsorption capacity reached $601 \mathrm{ng} / \mathrm{cm}^{2}$ in the absence of inhibitor, while decreased to $540 \mathrm{ng} / \mathrm{cm}^{2}$ when using $3000 \mathrm{ppm}$ cellobiose. Although the inhibition of Cel7B hydrolysis by cellobiose was also satisfactory at higher concentrations of 6000 and $12000 \mathrm{ppm}$, we selected $3000 \mathrm{ppm}$ as the optimized concentration of cellobiose to inhibit Cel7B hydrolysis. 

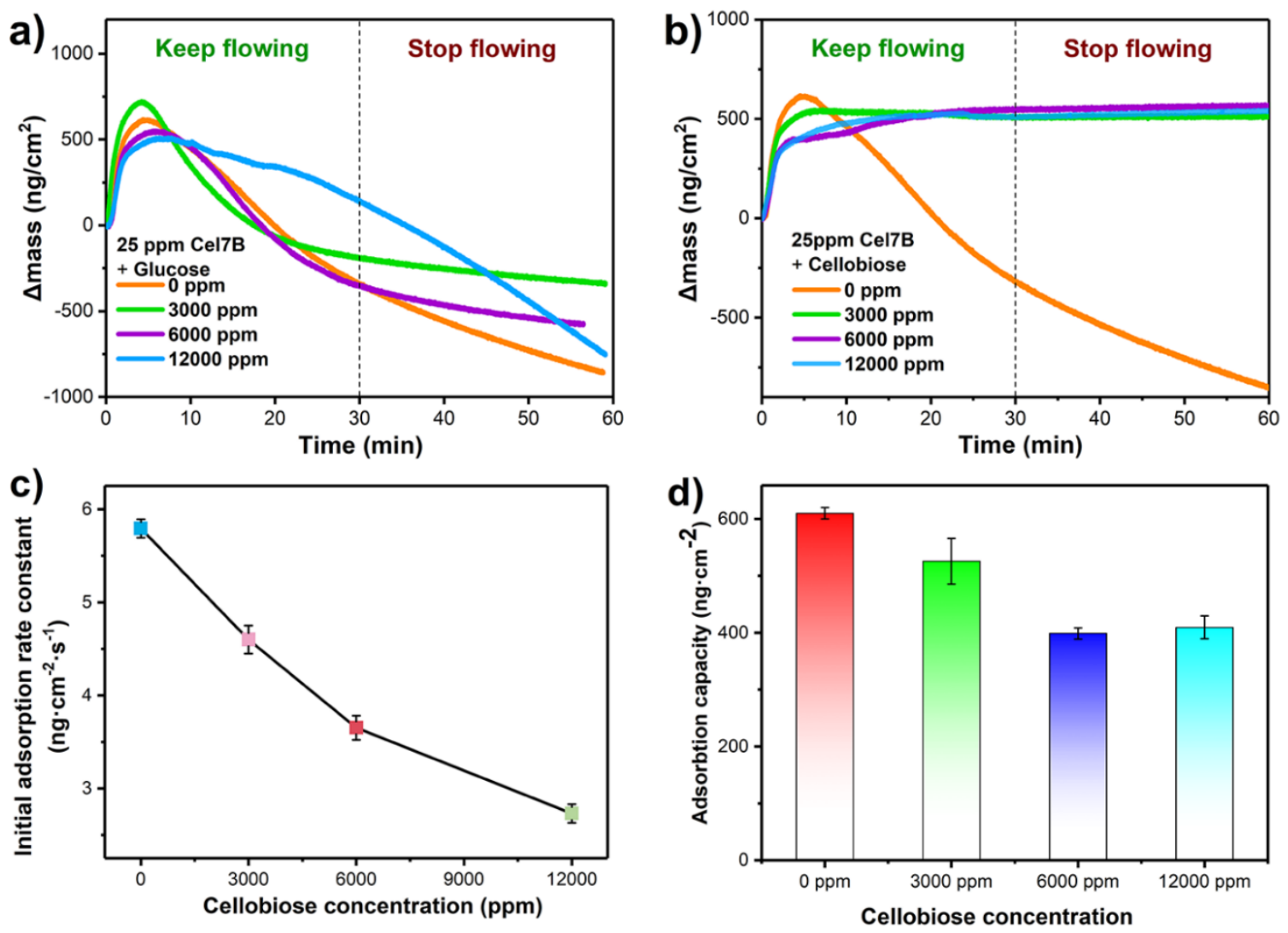

Figure 4. Effects of glucose and cellobiose on Cel7B adsorption on cellulose and its hydrolysis. The flow was stopped after $30 \mathrm{~min}$, as indicated by a vertical dashed line. Buffers containing (a) glucose and (b) cellobiose at concentrations of $0,3000,6000$, and $12000 \mathrm{ppm}$ were used. The concentration of Cel7B in aqueous buffer/inhibitor solutions equaled $25 \mathrm{ppm}$ at $25^{\circ} \mathrm{C}$. (c) Variation of initial adsorption rate constant with cellobiose concentration. (d) Variation of maximum enzyme adsorption capacity (achieved after $\sim 290$ s) with cellobiose concentration.

\section{Effect of pH on Cel7A adsorption}

Figure 5 illustrates the adsorption behavior and amount of Cel7A on cellulose films at different $\mathrm{pH}$ values. Specifically, Figure 5a reveals a sample mass-change history for the activity of a $50 \mathrm{ppm}$ Cel7A on a cellulose film at $\mathrm{pH} 6.0$ over a 75 min period. When Cel7A is exposed to the cellulose film, the amount of adsorbed enzyme sharply increased within the first $2 \mathrm{~min}$ and then increased very slowly to a 
constant value during 2-30 min. Since the above experiment was performed in the presence of $6000 \mathrm{ppm}$ glucose, it is believed that Cel7A adsorption on cellulose film was the main event during the initial $2 \mathrm{~min}$. After the maximum adsorption capacity had been reached, desorption was initiated by flushing the film with buffer solution (30-75 min), which eluted some adsorbed Cel7A. The desorption rate slowed down after 35-45 min of flushing, and the amount of Cel7A on the cellulose film could not be reduced to zero, i.e., the adsorbed Cel7A could not be completely eluted.
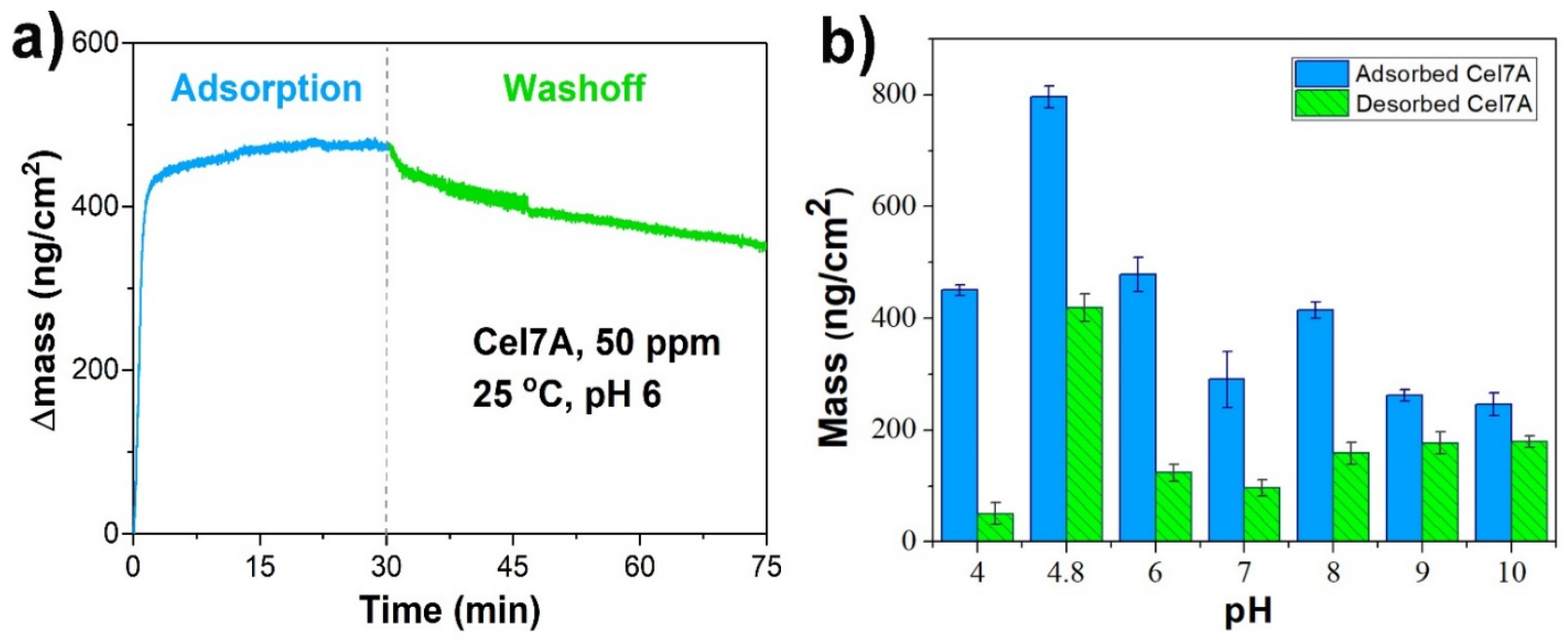

Figure 5. (a) Adsorption/desorption of Cel7A on cellulose at $\mathrm{pH}$ 6. The wash-off onset at time $=30 \mathrm{~min}$ is indicated by a vertical dashed line. (b) Cel7A adsorption and desorption capacities determined at different $\mathrm{pH}$ values at times of 30 and $60 \mathrm{~min}$, respectively. $50 \mathrm{ppm}$ Cel7 $\mathrm{A} / 6000 \mathrm{ppm}$ glucose solution in buffer was used at $25^{\circ} \mathrm{C}$.

Figure $5 \mathrm{~b}$ shows the maximum amounts of adsorbed/desorbed Cel7A obtained at different $\mathrm{pH}$ values after $30 \mathrm{~min}$ exposure. The highest adsorption capacity of $795.8 \mathrm{ng} / \mathrm{cm}^{2}$ was obtained at $\mathrm{pH} 4.8$. Notably, the adsorption capacity was relatively low at neutral and alkaline conditions. At $\mathrm{pH} 10$, the adsorption amount was only $245.8 \mathrm{ng} / \mathrm{cm}^{2}$. After 30 min desorption, the desorbed Cel7A at $\mathrm{pH} 10$ reached 179.5 $\mathrm{ng} / \mathrm{cm}^{2}$, accounting for $73.0 \%$ of the total adsorption capacity. Thus, alkaline conditions favored the 
removal of Cel7A from the cellulose substrates. Carbohydrate-binding modules (CBMs) is generally believed to directly affect the adsorption and motility of cellulase on cellulose. ${ }^{35-37}$ According to previous work, ${ }^{38}$ some cellulase might be trapped within the cellulose film and/or has cellulose chains trapped within the active site tunnel that prevents desorption, which explains why cellulase could not be completely desorbed from the substrate even after a very prolonged elution time. Another reason for only partial desorption may the entropic penalty that is paid upon desorption as water molecules need to restructure around the newly exposed surfaces upon desorption. The gain in entropy has previously been shown to be the driver for Bovine Serum Albumin adsorption onto modified cellulose nanocrystals. ${ }^{39}$

As shown in Figure 6a, a rapid adsorption within 2 min after Cel7B introduction was also observed at $\mathrm{pH} 4.0$, which was followed by a long and slower adsorption over the next 28 min after 30 min injection of enzyme solution, the adsorbed amount of Cel7B on the cellulose film exceeded that of Cel7A, which might be ascribed to the presence of more sites on the cellulose chains for Cel7B binding. Usually, Cel7A only binds to the ends of cellulose chains, whereas Cel7B can be adsorbed on random sites within these chains. Similar to Cel7A, some adsorbed Cel7B could not be desorbed even after a prolonged elution.

The adsorption capacities of Cel7B at pH 4 and 4.8 were 750.7 and $511.4 \mathrm{ng} / \mathrm{cm}^{2}$, respectively (Figure 6b), decreasing to only $240.8 \mathrm{ng} / \mathrm{cm}^{2}$ as the $\mathrm{pH}$ increased to 10 . Similar to Cel7A, the alkaline environment was not suitable for the adsorption of Cel7B, with optimal results observed at $\mathrm{pH} \leq 4.8$. Considering desorption, only $20 \%$ of adsorbed Cel7B could be eluted at $\mathrm{pH} 4$ and 4.8 , whereas $69.5 \%$ of adsorbed Cel7B could be eluted at $\mathrm{pH}$ 10. Thus, Cel7B was more also readily desorbed from cellulose substrates under alkaline conditions. In summary, both Cel7A and Cel7B exhibited easy-to-desorb behaviors under 
alkaline conditions, which was ascribed to their similar CBD structures. ${ }^{33}$ The $\mathrm{pH}$-dependent rate and extent of desorption of cellulases (Figures $5 \mathrm{~b}$ and $6 \mathrm{~b}$ ) might be due to the change in the binding energy with the increase of $\mathrm{pH}$. Remarkably, adjusting the solution $\mathrm{pH}$ is simpler and more cost-effective compared with adding other chemicals. ${ }^{40}$ This phenomenon is very useful to recover Cel7A and Cel7B from cellulosic substrates after enzymatic hydrolysis.
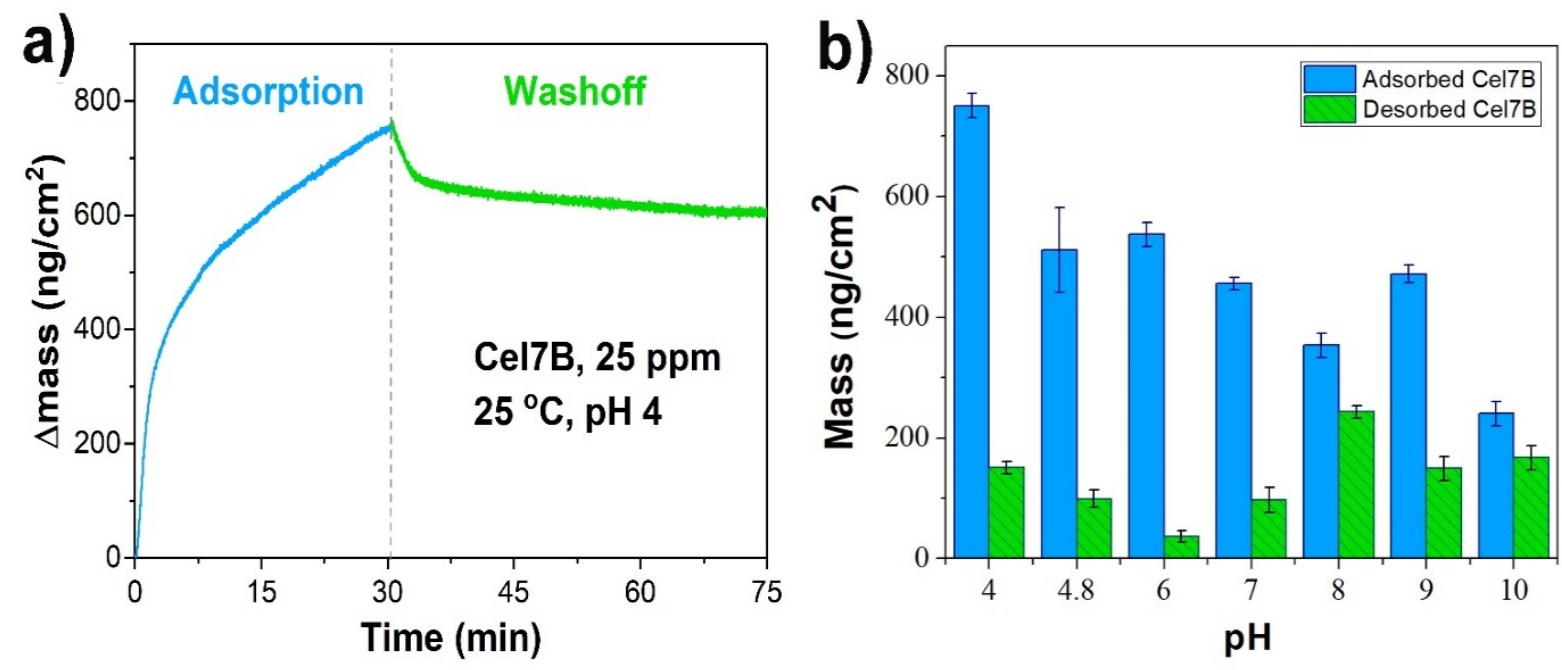

Figure 6. (a) Adsorption/desorption of Cel7B on cellulose at $\mathrm{pH}$ 4. The wash-off onset at time $=30 \mathrm{~min}$ is indicated by a vertical dashed line. (b) Cel7B adsorption and desorption capacities determined at different $\mathrm{pH}$ values at times of 30 and $70 \mathrm{~min}$, respectively. $25 \mathrm{ppm}$ Cel7B/3000 ppm cellobiose solution in buffer was used at $25^{\circ} \mathrm{C}$.

\section{Effect of temperature on Cel7A- and Cel7B-cellulose interactions}

Figure 7 displays the frequency-shift $(\Delta \mathrm{F})$ and energy-dissipation $(\Delta \mathrm{D})$ histories during the adsorption of Cel7A and Cel7B on cellulose films at 25 and $45{ }^{\circ} \mathrm{C}$. At $45{ }^{\circ} \mathrm{C}$, the fast adsorption of both Cel7A and Cel7B on the substrate surface in the absence of inhibitors was found and followed by fast hydrolysis of cellulose (Figures 7a and 7c), in contrast to the much slower hydrolysis behavior at $25{ }^{\circ} \mathrm{C}$ (Figures $7 \mathrm{e}$ and $7 \mathrm{~g}$ ). Based on the observed frequency minima, the addition of inhibitors to Cel7A and 
Cel7B did not significantly affect their adsorption capacities. At $45{ }^{\circ} \mathrm{C}$, the addition of inhibitors $(6000$ ppm glucose for Cel7A and 3000 ppm cellobiose for Cel7B) could inhibit enzymatic hydrolysis at a certain extent, but the cellulose film still underwent slow hydrolysis with a gradual increase in frequency. However, at $25^{\circ} \mathrm{C}$, the addition of inhibitors could greatly inhibit enzymatic hydrolysis. The increases in $D$ observed in the absence of inhibitors for Cel7A and Cel7B were significantly higher than those in the presence of inhibitors, which also indicated that the addition of the above inhibitors can slow down the change in film rigidity.

Under static conditions, without the flow of enzyme solutions (region II of Figures 7a and 7c), Cel7A continuously degraded cellulose chains, whereas the rate of Cel7B-catalyzed hydrolysis slowed down after $800 \mathrm{~s}$. At the same time, $D$ gradually decreased and approached equilibrium (Figure 7c), which indicated that at this point, Cel7B had hydrolyzed most of the amorphous cellulose and thus made the cellulose film more rigid, hence decreasing $D$. After the QCM-D experiment, we examined the contact angles of substrates which were tested at $45^{\circ} \mathrm{C}$ (Figure S4). The obtaining values of $55.2^{\circ}$ and $44.0^{\circ}$ were for films exposed to Cel7A and Cel7B in the absence of an inhibitor. In contrast, the relative contact angles were $14.5^{\circ}$ and $16.6^{\circ}$, respectively, for the substrates treated with inhibitor-containing solutions at $45^{\circ} \mathrm{C}$. Thus, enzymatic hydrolysis of cellulose films by Cel7A and Cel7B at $45{ }^{\circ} \mathrm{C}$ resulted in maximal hydrophobic area retention. 

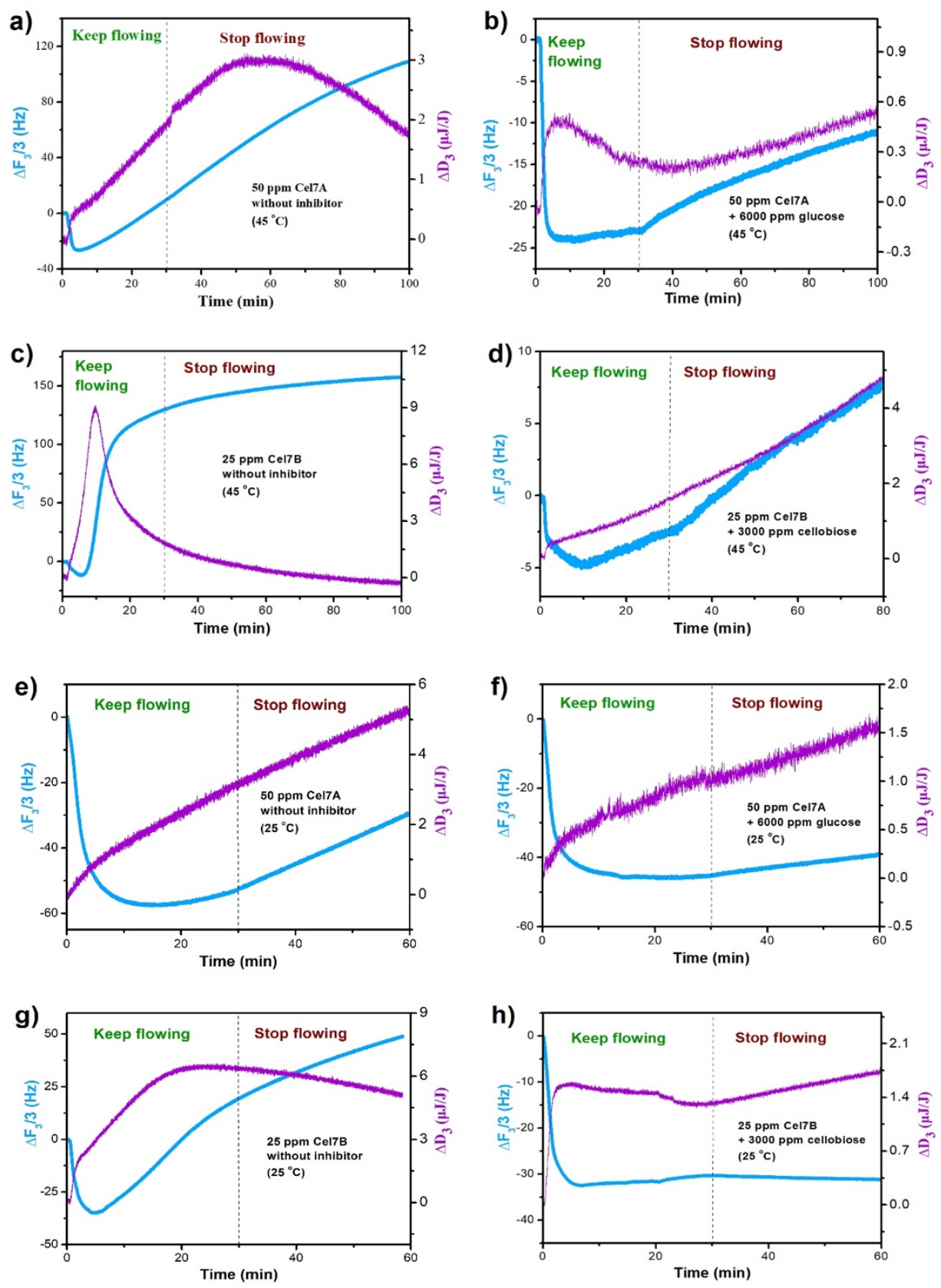

Figure 7. Frequency shift $\left(\Delta \mathrm{F}_{3} / 3\right.$ blue line $)$ and dissipation $\left(\Delta \mathrm{D}_{3}\right.$, purple line $)$ histories for the enzyme loading experiment. Adsorption/hydrolysis curves of Cel7A at $45{ }^{\circ} \mathrm{C}$ obtained in the absence of an inhibitor (a) and in the presence of $6000 \mathrm{ppm}$ glucose (b). Adsorption/hydrolysis curves of Cel7B obtained at $45{ }^{\circ} \mathrm{C}$ in the absence of an inhibitor (c) and in the presence of 3000 ppm cellobiose (d). Adsorption/hydrolysis curves of Cel7A obtained at $25{ }^{\circ} \mathrm{C}$ in the absence of an inhibitor (e) and in the presence of $6000 \mathrm{ppm}$ glucose (f). Adsorption/hydrolysis curves of Cel7B obtained at $25^{\circ} \mathrm{C}$ in the absence of an inhibitor (g) and in the presence of $3000 \mathrm{ppm}$ cellobiose (h). Regions marked keep flowing and stop flowing as regions I and II in the article, respectively. 


\section{CONCLUSIONS}

In summary, QCM-D investigation of cellulose films enabled a continuous assay of cellulase activity on cellulose film. This assay allowed us to follow the change in cellulose films and acquire the real-time adsorption behavior of cellulase. The addition of inhibitors (glucose or cellobiose with different concentrations) can obviously impede enzymatic degradation of cellulose, which is helpful to selectively investigate only the adsorption behavior of cellulases. Considering the effect of inhibition and the cost, $6000 \mathrm{ppm}$ of glucose and $3000 \mathrm{ppm}$ of cellobiose were applied as the inhibitors of Cel7A and Cel7B, respectively. Acidic conditions $(\mathrm{pH} \leq 4.8)$ were found to be more favorable for the adsorption of Cel7A and Cel7B on cellulose films, whereas the alkaline conditions ( $\mathrm{pH}$ at 9 and 10) were more favorable for desorption. Low temperature $\left(25^{\circ} \mathrm{C}\right)$ was helpful for the adsorption of enzymes, while a higher temperature of $45^{\circ} \mathrm{C}$ was beneficial for cellulose degradation.

\section{ASSOCIATED CONTENT}

Supporting Information

The Supporting Information is available free of charge on the ACS Publications website at DOI: 10.1021/acs.langmuir.8b02260.

Typical QCM-D curve and calculation; calculation of initial adsorption rate; AFM phase images of Cel7Atreated and Cel7B-treated surfaces; and contact angles of several surfaces.

\section{ABBREVIATIONS USED}

Quartz crystal microgravimetry with dissipation, QCM-D; cellobiohydrolase, CBH; endoglucanase, EG; poly-diallyl-dimethyl-ammonium chloride, PDADMAC; 4-methylmorpholine- $N$-oxide, 4MMO; dimethyl sulfoxide, DMSO; deionized, DI; atomic force microscopy, AFM; root mean square, RMS; 
Carbohydrate-binding modules, CBMs.

\section{AUTHOR INFORMATION}

\section{Corresponding Author}

*E-mail: surx@tju.edu.cn. Phone: +86 22 27407799. Fax: +86 22 27407599 (R.S.)

*Email: wim.thielemans@kuleuven.be Phone: +32 (0)56 24 6171. Fax: +32 (0)56 246997 (W.T.)

\section{ORCID}

Rongxin Su: 0000-0001-9778-9113

Wim Thielemans: 0000-0003-4451-1964

\section{Notes}

The authors declare no competing financial interest.

\section{ACKNOWLEDGMENTS}

This work was supported by the Natural Science Foundation of China (grant nos. 21776212, 21621004, and 21276192), and the Ministry of Education (grant nos. B06006 and NCET-11-0372). W.T. also thanks FWO for financial support through his Odysseus Fellowship (grant G.0C60.13N) and the Provincie West-Vlaanderen (Belgium) for his Chair in Advanced Materials.

\section{REFERENCES}

1. Menon, V.; Rao, M. Trends in bioconversion of lignocellulose: biofuels, platform chemicals \& biorefinery concept. Prog. Energ. Combust. 2012, 38, 522-550.

2. Sheridan, C. Big oil turns on biofuels. Nat. Biotechnol. 2013, 31, 870-873.

3. Goldemberg, J. Ethanol for a sustainable energy future. Science 2007, 315, 808-810.

4. Wu, K.; Ying, W.; Shi, Z.; Yang, H.; Zheng, Z.; Zhang, J.; Yang, J. Fenton reaction-oxidized bamboo 
lignin surface and structural modification to reduce nonproductive cellulase binding and improve enzyme digestion of cellulose. ACS Sustainable Chem. Eng. 2018, 6, 3853-3861.

5. Martín-sampedro, R.; Rahikainen, J. L.; Johansson, L. S.; Marjamaa, K.; Laine, J.; Kruus, K.; Rojas, O. J. Preferential adsorption and activity of monocomponent cellulases on lignocellulose thin films with varying lignin content. Biomacromolecules 2013, 14, 1231-1239.

6. Lu, X.; Wang, C.; Li, X., Zhao, J.; Zhao, X. Studying nonproductive adsorption ability and binding approach of cellobiohydrolase to lignin during bioconversion of lignocellulose. Energy Fuels 2017, $31,14393-14400$.

7. Pellegrini, V. O.; Lei, N.; Kyasaram, M.; Olsen, J. P.; Badino, S. F.; Windahl, M. S.; Westh, P. Reversibility of substrate adsorption for the cellulases Cel7A, Cel6A, and Cel7B from Hypocrea jecorina. Langmuir 2014, 30, 12602-12609.

8. Fritz, C.; Carrera, A. F.; Salas, C. L.; Jameel, H.; Rojas, O. J. On the interactions between cellulolytic enzymes with native, autohydrolysis and technical lignins and the effect of a polysorbate amphiphile in reducing non-productive binding. Biomacromolecules 2015, 16, 3878-3888.

9. Palonen, H.; Tjerneld, F.; Zacchi, G.; Tenkanen, M. Adsorption of Trichoderma reesei CBH I and EG II and their catalytic domains on steam pretreated softwood and isolated lignin. J. Biotechnol. 2004, $107,65-72$.

10. Huang, R. L.; Guo, H.; Su, R. X.; Qi, W.; He, Z. M. Enhanced cellulase recovery without $\beta$ glucosidase supplementation for cellulosic ethanol production using an engineered strain and surfactant. Biotechnol. Bioeng. 2017, 114, 543-551.

11. Zhang, M.; Su, R. X.; Li, Q.; Qi, W.; He, Z. M. Enzymatic saccharification of pretreated corn stover in a fed-batch membrane bioreactor. BioEnergy Res. 2011, 4, 134-140.

12. Haven, M. Ø.; Lindedam, J.; Jeppesen, M. D.; Elleskov, M.; Rodrigues, A. C.; Gama, M.; Felby, C. Continuous recycling of enzymes during production of lignocellulosic bioethanol in demonstration scale. Appl. Energ., 2015, 159, 188-195.

13. Gomes, D.; Rodrigues, A. C.; Domingues, L.; Gama, M. Cellulase recycling in biorefineries-is it possible? Appl. Microbiol. Biotechnol. 2015, 99, 4131-4143. 
14. Guo, J.; Catchmark, J. M. Binding specificity and thermodynamics of cellulose-binding modules from trichoderma reesei cel7a and cel6a. Biomacromolecules 2013, 14, 1268-77.

15. Badino, S. F.; Christensen, S. J.; Kari, J.; Windahl, M. S.; Hvidt, S., Borch, K.; Westh, P. Exo - exo synergy between Cel6A and Cel7A from hypocrea jecorina: role of carbohydrate binding module and the endo - lytic character of the enzymes. Biotechnol. Bioeng. 2017, 114, 1639-1647.

16. Zhang, K. D.; Li, W.; Wang, Y. F.; Zheng, Y. L.; Tan, F. C.; Ma, X. Q.; Yao, L. S.; Bayer, E. A.; Wang, L. S.; Li, F. L. Processive degradation of crystalline cellulose by a multimodular endoglucanase via a wirewalking mode. Biomacromolecules 2018, 19, 1686-1696.

17. Maurer, S. A.; Bedbrook, C. N.; Radke, C. J. Cellulase adsorption and reactivity on a cellulose surface from flow ellipsometry. Ind. Eng. Chem. Res. 2012, 51, 11389-11400.

18. Du, R. Y.; Su, R. X.; Li, X.; Tantai, X. W.; Liu, Z. H.; Yang, J. F.; Qi, W.; He, Z. M. Controlled adsorption of cellulase onto pretreated corncob by pH adjustment. Cellulose 2012, 19, 371-380.

19. Turon, X.; Rojas, O. J.; Deinhammer, R. S. Enzymatic kinetics of cellulose hydrolysis: a QCM-D study. Langmuir 2008, 24, 3880-3887.

20. Su, R. X.; Chen, M. M.; Huang, R. L.; Qi, W.; Wang, M. F.; He, Z. M. QCM-D Analysis of film formation and enzymatic hydrolysis of lignocellulose. Journal of Tianjin University (Science and Technology) 2018, 51, 1-8.

21. Cheng, G.; Liu, Z.; Murton, J. K.; Jablin, M.; Dubey, M.; Majewski, J.; Halbert, C.; Browning, J.; Ankner, J.; Akgun, B.; Wang, C.; Esker, A. R.; Sale, K. L.; Simmons, B. A.; Kent, M. S. Neutron reflectometry and QCM-D study of the interaction of cellulases with films of amorphous cellulose. Biomacromolecules 2011, 12, 2216-2224.

22. Holtzapple, M.; Cognata, M.; Shu, Y.; Hendrickson, C. Inhibition of Trichoderma reesei, cellulase by sugars and solvents. Biotechnol. Bioeng. 1990, 36, 275-287.

23. Kristensen, J. B.; Felby, C.; Jørgensen, H. Yield-determining factors in high-solids enzymatic hydrolysis of lignocellulose. Biotechnol. Biofuels 2009, 2, 11-21.

24. Maurer, S. A.; Bedbrook, C. N.; Radke, C. J. Competitive sorption kinetics of inhibited endo- and exoglucanases on a model cellulose substrate. Langmuir 2012, 28, 14598-14608. 
25. Levine, S. E.; Fox, J. M.; Blanch, H. W.; Clark, D. S. A mechanistic model of the enzymatic hydrolysis of cellulose. Biotechnol. Bioeng. 2010, 107, 37-51.

26. Bharadwaj, R.; Wong, A.; Knierim, B.; Singh, S.; Holmes, B. M.; Auer, M.; Simmons, B. A.; Adams, P. D.; Singh, A. K. High-throughput enzymatic hydrolysis of lignocellulosic biomass via in-situ regeneration. Bioresour. Technol. 2011, 102, 1329-1337.

27. Maurer, S. A.; Brady, N. W.; Fajardo, N. P.; Radke, C. J. Surface kinetics for cooperative fungal cellulase digestion of cellulose from quartz crystal microgravimetry. J. Colloid Interface Sci. 2013, 394, 498-508.

28. Gunnars, S.; Wågberg, L.; Stuart, M. A. C. Model films of cellulose: I. Method development and initial results. Cellulose 2002, 9, 239-249.

29. Sauerbrey, G. Verwendung von Schwingquarzen zur Wägung dünner Schichten und zur Mikrowagung. Z. Phys. 1959, 155, 206-222.

30. Mohan, T.; Kargl, R.; Doliška, A.; Vesel, A.; Köstler, S.; Ribitsch, V.; Stana-Kleinschek, K. Wettability and surface composition of partly and fully regenerated cellulose thin films from trimethylsilyl cellulose. J. Colloid Interface Sci. 2011, 358, 604-610.

31. Olsen, J. P.; Alasepp, K.; Kari, J.; Cruys-Bagger, N.; Borch, K.; Westh, P. Mechanism of product inhibition for cellobiohydrolase Cel7A during hydrolysis of insoluble cellulose. Biotechnol. Bioeng. 2016, 113, 1178-1186.

32. Gruno, M.; Väljamäe, P.; Pettersson, G.; Johansson, G. Inhibition of the Trichoderma reesei cellulases by cellobiose is strongly dependent on the nature of the substrate. Biotechnol. Bioeng. 2004, 86, 503511.

33. Srisodsuk, M.; Lehtiö, J.; Linder, M.; Margollesclark, E.; Reinikainen, T.; Teeri, T. T. Trichoderma reesei cellobiohydrolase I with an endoglucanase cellulose-binding domain: action on bacterial microcrystalline cellulose. J. Biotechnol. 1997, 57, 49-57.

34. Andresen, M.; Johansson, L. S.; Tanem, B. S.; Stenius, P. Properties and characterization of hydrophobized microfibrillated cellulose. Cellulose 2006, 13, 665-677.

35. Liu, Y. S.; Zeng, Y.; Luo, Y.; Xu, Q.; Himmel, M. E.; Smith, S. J.; Ding, S. Y. Does the cellulose- 
binding module move on the cellulose surface? Cellulose 2009, 16, 587-597.

36. Xu, Q.; Song, Q.; Ai, X.; Mcdonald, T. J.; Long, H.; Ding, S. Y.; Himmel, M. E.; Rumbles, G. Engineered carbohydrate-binding module (CBM) protein-suspended single-walled carbon nanotubes in water. Chem. Commun. 2009, 3, 337-339.

37. Dagel, D. J.; Liu, Y. S.; Zhong, L.; Luo, Y.; Himmel, M. E.; Xu, Q.; Zeng, Y.; Ding, S. Y.; Smith, S. In situ imaging of single carbohydrate-binding modules on cellulose microfibrils. J. Phys. Chem. B. 2011, 115, 635-641.

38. Gao, D.; Haarmeyer, C.; Balan, V.; Whitehead, T. A.; Dale, B. E.; Chundawat, S. P. Lignin triggers irreversible cellulase loss during pretreated lignocellulosic biomass saccharification. Biotechnol Biofuels 2014, 7, 175-188.

39. Lombardo, S.; Eyley S.; Schütz, C.; Van Gorp, H.; Rosenfeldt, S.; Van den Mooter, G.; Thielemans, W. Thermodynamic study of the interaction of bovine serum albumin and amino acids with cellulose nanocrystals. Langmuir 2017, 33, 5473-5481.

40. Zhu, Z.; Sathitsuksanoh, N.; Zhang, Y. H. P. Direct quantitative determination of adsorbed cellulase on lignocellulosic biomass with its application to study cellulase desorption for potential recycling. Analyst, 2009, 134, 2267-2272. 
Table of Contents/Abstract art/Synopsis

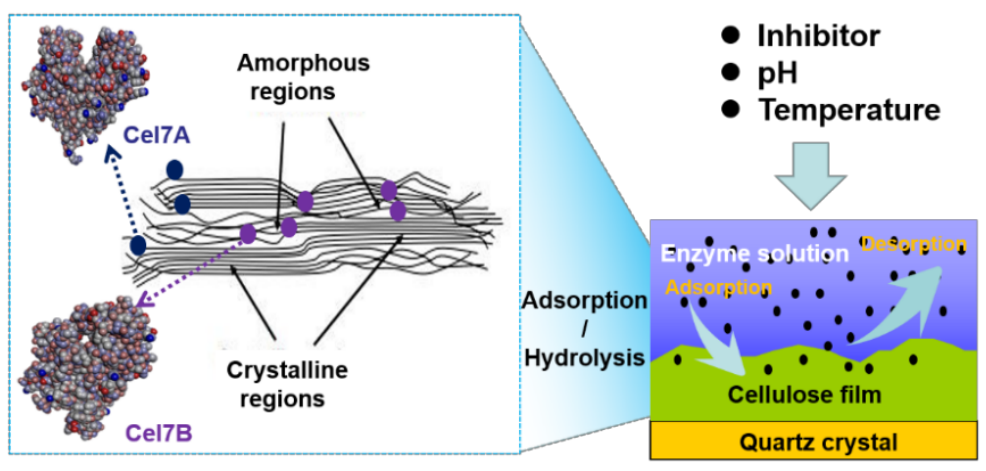

